Sensors 2003, 3, 509-523

sensors

ISSN 1424-8220

(C) 2003 by MDPI

http://www.mdpi.net/sensors

\title{
Iodide Selective Electrodes Based on Bis(2-mercaptobenzo- thiazolato) Mercury(II) and Bis(4-chlorothiophenolato) Mercury(II) Carriers
}

\author{
Mohammad K. Amini*, Mehrorang Ghaedi, Ali Rafi, Mohammad. H. Habibi and Morteza M. \\ Zohory
}

Chemistry Department, University of Isfahan, Isfahan 81746-73441, Iran

* Author to whom correspondence should be addressed. Tel. (+98)-311-7932708, Fax: (+98)-3116689732, E-mail: mkamini@ sci.ui.ac.ir

Received: 16 August 2003 / Accepted: 12 October 2003 / Published: 5 December 2003

\begin{abstract}
New iodide-selective electrodes based on bis(2-mercaptobenzothiazolato) mercury(II) $\left[\mathrm{Hg}(\mathrm{MBT})_{2}\right]$ and bis(4-chlorothiophenolato) mercury(II) $\left[\mathrm{Hg}(\mathrm{CTP})_{2}\right]$ carriers are described. The electrodes were prepared by incorporating the ionophores into plasticized PVC membranes, which were directly coated on the surface of graphite disk electrodes. The electrodes displayed high selectivity for iodide with respect to a number of inorganic and organic anions. The influence of the membrane composition and $\mathrm{pH}$, and the effect of lipophilic cationic and anionic additives on the response properties of the electrodes were investigated. The electrodes exhibited near-Nernstian slopes of $-57.6 \pm 0.8$ and $-58.4 \pm 1.4$ $\mathrm{mV} /$ decade of iodide concentration over the range $1 \times 10^{-6}-1 \times 10^{-1} \mathrm{M}$, with detection limits of $\sim 4 \times 10^{-7}$ and $6 \times 10^{-7} \mathrm{M}$ for the electrodes based on $\left[\mathrm{Hg}(\mathrm{MBT})_{2}\right]$ and $\left[\mathrm{Hg}(\mathrm{CTP})_{2}\right]$, respectively. They have relatively fast response times $(\leq 10 \mathrm{~s})$, satisfactory reproducibility, and life times of at least two months. The potentiometric responses of the electrodes are independent of $\mathrm{pH}$ of the test solution over the range $3.5-11.5$.
\end{abstract}

Keywords: Iodide selective electrode; Potentiometric sensors; Bis(2mercaptobenzothiazolato) mercury (II); Bis(4-chlorothiophenolato) mercury(II); Coatedgraphite electrode 


\section{Introduction}

Due to the importance of iodine as an essential micronutrient and its key role in many biological activities such as brain function, cell growth, neurological activities and thyroid function [1], numerous analytical methods have been reported for its determination at low concentration levels. These include gas chromatography with mass spectrometry detection [2]; ion chromatography with spectrophotometry [3] or mass spectrometry [4] detection; inductively coupled plasma atomic emission mass spectrometry [5]; neutron activation analysis [6]; chemiluminescence [7]; polarography [8]; cathodic [9] and anodic stripping voltammetry [10,11]; flow injection methods based on amperometry [1], spectrophotometry [12] or catalytic [13] detection; and potentiometry based on ionselective electrodes (ISEs). Most of these methods require expensive instrumentation, rather complicated techniques, and/or sample pretreatments. Among these methods, ISEs offer unique advantages such as simplicity, speed of analysis, low cost, wide linear range, reasonable selectivity and non-destructive analysis, and as such, have emerged as one of the most promising tools for direct and easy determination of various species.

One of the most important figures of merit for an ISE is its selectivity towards a specific analyte, which is generally limited by the interaction of the ionophore within the membrane with other ions. The selectivity of ISEs is generally governed by specific and non-specific interactions. Specific interactions are based on chemical recognition principle, where a recognition element such as metalligand interaction is used to achieve the required selectivity. Non-specific interactions, which are generally governed by the so-called Hofmeister pattern, are based on both lipophilicity and electrostatic interactions. Therefore, these interactions are essentially "non-selective" [14]. Most of the recently reported anion-selective electrodes are based on specific type of interactions, where complexes of suitable ligands with several metal ions have been employed in the design of "truly" anion-selective electrodes for different anions. It has been shown that the anion selectivity of the membrane electrodes that are based on metal complexes is influenced by both the structure of the ligands and the properties of the metal ions $[14,15]$.

The wide use of ISEs in routine chemical analysis have accompanied by a search for ionophores that offer improved potentiometric response characteristics. Several iodide- selective electrodes, which are based on the relatively selective interaction of transition metal complexes with iodide, have been reported. Polymeric membranes containing a complex of triisobutylphosphine sulfide and either $\mathrm{Ag}^{+}$or

$\mathrm{Hg}^{2+}$ have been reported for iodide $[15,16]$. Although these electrodes show good selectivity for iodide with respect to several anions, they have fairly long response times. Other complexes of $\mathrm{Ag}(\mathrm{I})$ with sulfur containing ligands, such as thiocarbamoylimine-dithioether derivatives [17] and silver thiourea complex [18] have been proposed as carriers for iodide-selective electrodes. ISE membranes of mercurated polystyrene containing a large number of $\mathrm{RC}_{4} \mathrm{H}_{4} \mathrm{HgOAC}$ units [19,20]; a Schiff base type complex of $\mathrm{Hg}$ (II) [21]; several complexes of $\mathrm{Co}$ (II) and $\mathrm{Ni}$ (II) with various ligands such as $\mathrm{Co}$ (II) Schiff bases [22,23], nickel tetraazaannulene macrocyclic complex [24], cobalt and nickel cyclam derivatives [25], covalently attached cobalt phthalocyanine [26], and a vitamin $\mathrm{B}_{12}$ analog [27]; complexes of other transition metal ions such as Mn(II)-salen [28] and a Schiff base complex of Fe(III) [29], also have been reported. Potentiometric response of the membranes doped with these complexes is believed to be based on the selective coordination of iodide to the metal center in the carrier 
molecules. Among these ionophores, silver and mercury complexes, seem to have a higher tendency for the soft iodide ion, as indicated by their relatively high selectivity for this ion with respect to several other anions. There are a few reports on the use of mercury complexes or mercury bearing polymers, such as mercury triisobutylphosphine sulfide [15], mercury Schiff bases [21], and mercurated polystyrene [19,20], for the construction of iodide-selective electrodes.

The purpose of this work was the development of iodide-selective electrodes based on plasticized PVC membranes, containing $\mathrm{Hg}(\mathrm{MBT})_{2}$ and $\mathrm{Hg}(\mathrm{CTP})_{2}$ as the membrane active ingredients, coated on the surface of graphite disk electrodes. Coated type electrodes are very easy to construct and handle, and offer much higher mechanical resistance, compared to their liquid membrane counterparts. As such, these electrodes can be applied in flowing streams and as microelectrodes for in-situ analysis. Further, they can be easily regenerated by dipping the electrodes into the membrane solution. Different types of solid-contact electrodes have been successfully applied in various fields of applications, such as flow-injection analysis [30,31], capillary electrophoresis [32-34], and direct or indirect determination of many cationic and anionic species [35-45]. In this work, the selectivity for a variety of ions and the effect of membrane matrix, ionophore concentration, additives, and $\mathrm{pH}$ on the potentiometric response properties of the proposed electrodes were investigated.

\section{Experimental}

\section{Reagents}

Dibutyl phthalate (DBP), sodium tetraphenylborate (NaTPB), dioctylphthalate (DOP), bis(2ethylhexyl) sebacate (BEHS), methyltrioctylammoniun chloride (MTOAC), tetrahydrofuran (THF) and high relative molecular weight PVC were purchased from Aldrich and were used as received, except THF which was distilled before use. The compounds used for preparation of complexes including 2-mercaptobenzothiazole, 4-chlorothiophenol, methanol, dimethylformamide (DMF), diethyl ether, mercury acetate, acetone, and all other chemicals were of highest purity available from Fluka, and were used without further purification. Stock $0.1 \mathrm{M}$ iodide solutions were prepared daily from potassium iodide. All aqueous solutions were prepared with deionized, distilled water. Mercury complexes of 2-mercaptobenzothiazole and 4-chlorothiophenol were synthesized and purified according to previously reported procedures $[46,47]$. The $\mathrm{pH}$ adjustments were made with dilute nitric acid or sodium hydroxide solutions as required.

\section{Preparation of electrodes}

The coated-graphite electrodes were prepared according to a previously reported method [44]. Graphite rods ( $3 \mathrm{~mm}$ diameter and $10 \mathrm{~mm}$ long) were prepared from spectroscopic grade graphite. A shielded copper wire was glued to one end of the graphite rod with silver loaded epoxy resin, and the rod was inserted into the end of a PVC tube. The working surface of the electrode was polished with a polishing cloth. The electrode was rinsed with water and methanol and allowed to dry. A mixture of PVC, plasticizer and the membrane additive (MTOAC), to give a total mass of $100 \mathrm{mg}$, was dissolved in about $5 \mathrm{ml}$ of THF. To this mixture was added the electroactive material, $\mathrm{Hg}(\mathrm{MBT})_{2}$ or $\mathrm{Hg}(\mathrm{CTP})_{2}$, and the solution was mixed well. The polished graphite electrode was then coated, by repeated dipping 
(several times, a few minutes between dips) into the membrane solution. A membrane was formed on the graphite surface, which was allowed to set overnight. The electrode was rinsed with water and conditioned for $\sim 18 \mathrm{~h}$ in $0.05 \mathrm{M}$ potassium iodide solution. The coating solutions are stable for several weeks if kept in refrigerator and can be used for the construction of new membranes.

\section{Apparatus and potential measurement}

All potential measurements were carried out with the following cell assembly: $\mathrm{Hg} / \mathrm{Hg}_{2} \mathrm{Cl}_{2} / \mathrm{KCl}$ (sat'd.) I| test solution I PVC membrane I graphite electrode. All the potential measurements were carried out with a digital $\mathrm{pH} / \mathrm{Ion}$ meter, model 692 Metrohm at $25.0 \pm 0.1{ }^{\circ} \mathrm{C}$. The $\mathrm{pH}$ of the sample solutions was monitored simultaneously with a conventional glass $\mathrm{pH}$ electrode. The performance of each electrode was investigated by measuring its potential in potassium iodide solutions prepared in the concentration range $1 \times 10^{-1}-1 \times 10^{-7} \mathrm{M}$ by serial dilution of the $0.1 \mathrm{M}$ stock solution at constant $\mathrm{pH}$. The solutions were stirred and potential readings recorded when they reached steady state values. The data were plotted as observed potential versus the logarithm of I' concentration. The spectra of the complexes were recorded with a Varian model Cary-500 spectrophotometer using a $1 \mathrm{~cm}$ quartz cells.

\section{Results and discussion}

The coated graphite electrodes based on $\mathrm{Hg}(\mathrm{MBT})_{2}$ and $\mathrm{Hg}(\mathrm{CTP})_{2}$ complexes in PVC membranes incorporating DBP as plasticizer and MTOAC as the membrane additive were highly selective to iodide ion with respect to several anions. The electrodes behave reversibly in iodide solutions of different concentrations and have fast exchange kinetic, as they reached stable potentials in $\leq 10 \mathrm{~s}$. The selectivity of the electrodes for iodide ion with respect to several anions, such as perchlorate, salicylate, nitrate, nitrite and thiocyanate ( $\log K_{\mathrm{I}^{-}, \mathrm{J}^{-}},-2.6,-4.0,-4.9,-4.8$, and -1.2 to -2.4 , respectively) indicate that there is a relatively specific interaction between the carriers and iodide ion. In fact, the membrane electrodes based on both mercury complexes behave on the basis of a specific type of interaction. The preferential response of the membranes based on these carriers toward iodide ion is believed to be associated with the selective coordination of this anion to the mercury center in the complexes. The selectivity of the electrodes with respect to halide ions show the trend $\mathrm{I}^{-}>\mathrm{Br}^{-}>\mathrm{Cl}^{-}\left(\log K_{\mathrm{I}^{-}, \mathrm{J}^{-}}, \sim-3.0\right.$ and -3.5 for bromide and chloride ions, respectively), which follows all of the stepwise stability orders of the halide-mercury complexes in solution (Table 1) [48]. This also may be taken as a good indication for the selective interaction of iodide with mercury carriers in the membranes. The strong deviation from the Hofmeister selectivity pattern: $\mathrm{ClO}_{4}{ }^{-}>\mathrm{SCN}^{-}>$Salicylate $>\mathrm{I}^{-}>\mathrm{NO}_{3}{ }^{-}>\mathrm{Br}^{--}>\mathrm{N}_{3}{ }^{-}$ $>\mathrm{NO}_{2}{ }^{-}>\mathrm{Cl}^{-}>\mathrm{CH}_{3} \mathrm{COO}^{-}>\mathrm{SO}_{4}{ }^{2-}$, observed for several highly lipophilic anions, also can be described correspondingly. From the UV-Vis spectra of $\mathrm{Hg}(\mathrm{MBT})_{2}$ and $\mathrm{Hg}(\mathrm{CTP})_{2}$ complexes with iodide in chloroform solutions, obtained at a fixed concentration of the carriers and increasing amounts of iodide, typically shown in Figure 1 for $\mathrm{Hg}(\mathrm{MBT})_{2}$, it was possible to distinguish the interaction between the central metal and iodide. The substantial increase in absorbances at $320 \mathrm{~nm}$ for $\mathrm{Hg}(\mathrm{MBT})_{2}$-iodide and at $\sim 300 \mathrm{~nm}$ for $\mathrm{Hg}(\mathrm{CTP})_{2}$-iodide systems were observed after addition of iodide to the solutions containing the complexes. It should be mentioned that $\mathrm{Hg}(\mathrm{MBT})_{2}$ and $\mathrm{Hg}(\mathrm{CTP})_{2}$ complexes have very low solubility in aqueous solutions, which minimize their leaching from the membrane and 
contamination of the sample solutions. This, together with their high tendency towards the soft iodide ion, makes the proposed carriers useful for construction of iodide-selective electrodes.

Table 1. Stability Constants of Mercury Halide Complexes.

\begin{tabular}{|l|c|c|c|c|}
\hline Complex & $\log \mathbf{K}_{\mathbf{1}}$ & $\log \mathbf{K}_{\mathbf{2}}$ & $\log \mathbf{K}_{\mathbf{3}}$ & $\log \mathbf{K}_{\mathbf{4}}$ \\
\hline $\mathrm{HgI}_{4}{ }^{2-}$ & 12.9 & 11.0 & 3.8 & 2.3 \\
\hline $\mathrm{HgBr}_{4}{ }^{2-}$ & 9.0 & 8.3 & 1.4 & 1.3 \\
\hline $\mathrm{HgCl}_{4}{ }^{2-}$ & 6.7 & 6.5 & 0.9 & 1.0 \\
\hline
\end{tabular}

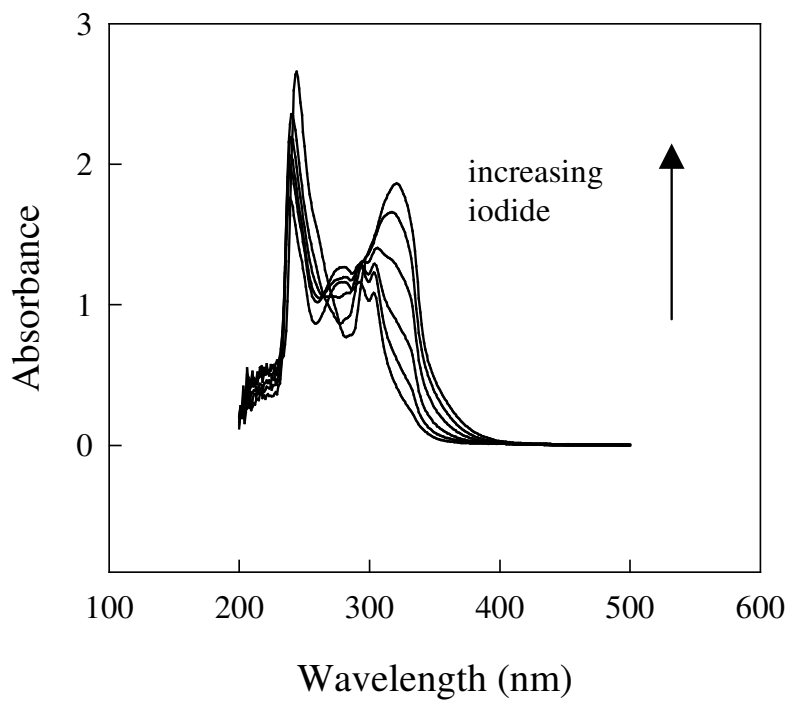

Figure 1. UV-Vis spectra of $5 \times 10^{-5} \mathrm{M} \mathrm{Hg}(\mathrm{MBT})_{2}$ complex after addition of several iodide increments $\left(\mathrm{I}^{-} / \mathrm{Hg}(\mathrm{MBT})_{2}\right.$ mole ratios of $0.25,0.5,1,2$ and 4$)$ in chloroform solutions.

\section{Influence of the membrane composition}

Different membrane compositions were prepared by varying the concentration of the carriers, the nature and amount of plasticizer, and concentration of the membrane additive. The influence of these parameters on the response characteristics of the electrodes were investigated in iodide concentrations in the range $1 \times 10^{-7}-0.1 \mathrm{M}$.

The amount of carrier was changed while the ratios of $\mathrm{PVC} /$ plasticizer and $\mathrm{MTOAC} / \mathrm{carrier}$ concentrations were the same for all of the membranes. The working range and sensitivity of the electrode response were improved on increasing the concentration of $\mathrm{Hg}(\mathrm{MBT})_{2}$ or $\mathrm{Hg}(\mathrm{CTP})_{2}$ up to $5 \%$. Further addition of the carrier concentration worsened the electrode response, most probably due to saturation or non-uniformity of the membrane. The electrodes with no carrier (blank membranes, containing PVC, plasticizer and MTOAC) displayed insignificant selectivity and sensitivity towards iodide. 
The influence of plasticizer type on the response characteristics of the iodide electrodes was investigated by using five plasticizers of different polarities including DBP, DOP, NPPE, DOPP and BEHS. In all cases the plasticizer/PVC mass ratio of 2 resulted in highest sensitivity. Among the several membranes tested for each of the carriers, the membranes incorporating DBP generally showed better potentiometric responses, i.e., higher sensitivity and wider linearity of the calibration plots. It seems that DBP, as a low polarity and a relatively high mobility, with respect to other plasticizers examined, provides appropriate conditions for incorporation of highly lipophilic iodide ion into the membranes prior to its coordination with the mercury atom in the complexes.

The influence of the type and concentration of the membrane additives were also investigated by incorporating MTOAC or NaTPB into the membranes. The potentiometric sensitivity of the membranes based on both carriers was greatly improved in the presence of MTOAC as a lipophilic cationic additive, compared to the membranes with no additive at all. No anionic response was observed when the anionic additive, NaTPB, was incorporated. Previous studies have shown that there is an optimal concentration of lipophilic ionic additives in the membranes that gives the best electrode performance. The effect of MTOAC concentration in the membrane was investigated at several additive/carrier mole ratios. Generally the electrodes with MTOAC/carrier mole ratios of $\sim 0.55$ for both of the carriers exhibited maximum sensitivity over a wide range of iodide concentration. Among the different membrane compositions studied, membranes with 5.0\% carrier, $2.1-2.3 \%$ MTOAC, $31.0 \%$ PVC and 62.0\% DBP (MTOAC/carrier mole ratio of $~ 0.55$ ), which showed highest sensitivity and widest linear range, were selected as the optimum composition for further studies (Table 2).

Table 2. Specifications of the Iodide-Selective Electrodes Based on $\operatorname{Hg}(\mathrm{CTP})_{2}$ and $\mathrm{Hg}(\mathrm{MBT})_{2}$ Carriers.

\begin{tabular}{|c|c|c|}
\hline \multirow[b]{2}{*}{ Properties } & \multicolumn{2}{|c|}{ Values / Range } \\
\hline & $\mathbf{H g}(\mathrm{MBT})_{2}$ & $\operatorname{Hg}(\mathrm{CTP})_{2}$ \\
\hline $\begin{array}{l}\text { Optimized membrane composition (\% by } \\
\text { weight) }\end{array}$ & $\begin{array}{l}\text { PVC }(31.0), \text { DBP }(61.9), \\
\operatorname{Hg}(\operatorname{MBT})_{2}(5.0), \\
\operatorname{MTOAC}(2.1) \\
\text { MTOAC/Hg }(\mathrm{MBT})_{2} \\
\text { mole ratio }=0.55\end{array}$ & $\begin{array}{l}\text { PVC }(30.9), \text { DOP } \\
(61.8), \mathrm{Hg}(\mathrm{CTP})_{2}(5.0), \\
\text { MTOAC }(2.3) \\
\text { MTOAC } / \mathrm{Hg}(\mathrm{CTP})_{2} \\
\text { mole ratio }=0.56 \\
\end{array}$ \\
\hline Electrode type & \multicolumn{2}{|c|}{ Coated-graphite (solid contact) electrode } \\
\hline $\mathrm{pH}$ range & \multicolumn{2}{|l|}{$3.5-11$ for both electrodes } \\
\hline Conditioning time & \multicolumn{2}{|l|}{ at least $18 \mathrm{~h}$ in $0.05 \mathrm{M} \mathrm{KI}$} \\
\hline Linear range $\left(\mathrm{I}^{-}, \mathrm{M}\right)$ & $1 \times 10^{-6}-1 \times 10^{-1}$ & $1 \times 10^{-6}-1 \times 10^{-1}$ \\
\hline Slope (mV/decade) & -57.6 & -58.4 \\
\hline Detection limit (M) & $4 \times 10^{-7}$ & $6 \times 10^{-7}$ \\
\hline $\begin{array}{l}\text { Standard deviation of slope (within } \\
\text { electrode variation, } \mathrm{mV} / \text { decade) }\end{array}$ & \pm 0.8 & \pm 1.4 \\
\hline
\end{tabular}




\begin{tabular}{|c|c|c|}
\hline \multirow[b]{2}{*}{ Properties } & \multicolumn{2}{|c|}{ Values / Range } \\
\hline & $\mathbf{H g}(\mathrm{MBT})_{2}$ & $\operatorname{Hg}(\mathrm{CTP})_{2}$ \\
\hline $\begin{array}{l}\text { Optimized membrane composition (\% by } \\
\text { weight) }\end{array}$ & $\begin{array}{l}\text { PVC }(31.0), \text { DBP (61.9), } \\
\operatorname{Hg}(\operatorname{MBT})_{2}(5.0), \\
\text { MTOAC }(2.1) \\
\text { MTOAC } / \mathrm{Hg}(\mathrm{MBT})_{2} \\
\text { mole ratio }=0.55\end{array}$ & $\begin{array}{l}\text { PVC }(30.9), \text { DOP } \\
(61.8), \mathrm{Hg}(\mathrm{CTP})_{2}(5.0), \\
\text { MTOAC }(2.3) \\
\text { MTOAC } / \mathrm{Hg}(\mathrm{CTP})_{2} \\
\text { mole ratio }=0.56\end{array}$ \\
\hline \begin{tabular}{|} 
Standard deviation of slope (between \\
electrode variation, RSD\%) \\
during 15 days in: & $0.05 \mathrm{M} \mathrm{KI}$ \\
& ambient air \\
& distilled water \\
during 1 month in: & $0.05 \mathrm{M} \mathrm{KI}$ \\
& ambient air \\
distilled water
\end{tabular} & $\begin{array}{l} \pm 1.7 \\
\pm 2.3 \\
\pm 3.8 \\
\pm 2.5 \\
\pm 3.5 \\
\pm 4.3\end{array}$ & \\
\hline Response time (s) & $\leq 10$ & $\leq 10$ \\
\hline
\end{tabular}

Response characteristics and selectivity of the electrodes

The optimum equilibration time and concentration of the conditioning solution for both electrodes were $18 \mathrm{~h}$ in $0.05 \mathrm{M}$ potassium iodide solution, after which the electrodes generated stable potential responses.

The behavior of the coated membrane electrodes based on $\mathrm{Hg}(\mathrm{MBT})_{2}$ and $\mathrm{Hg}(\mathrm{CTP})_{2}$ ionophores was investigated at different $\mathrm{pH}$ values using $1 \times 10^{-3}$ and $1 \times 10^{-2} \mathrm{M}$ iodide solutions. The potential responses of the electrodes based on both carriers are almost independent of $\mathrm{pH}$ over the range $2.5-11$ or $3.5-11$, depending on the iodide concentration (Figure 2). The maximum change $\Delta \mathrm{E} / \Delta \mathrm{pH}$ was $\sim 1$ $\mathrm{mV}$, indicating that $\mathrm{OH}^{-}$can not compete with iodide ion, and do not interfere even at high $\mathrm{pH}$ values.

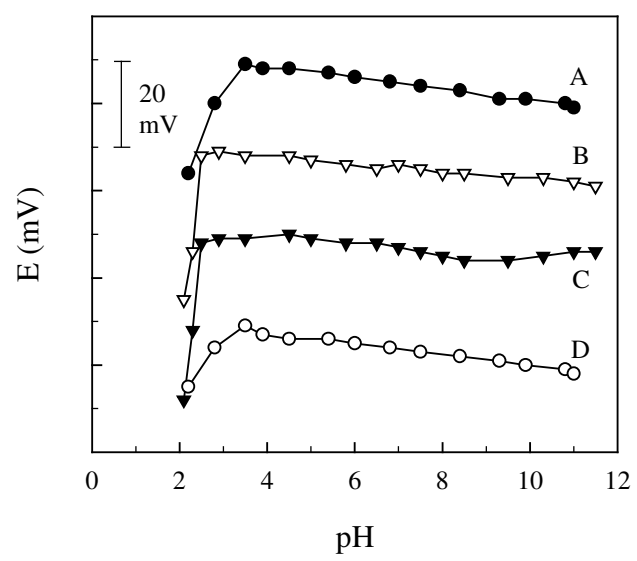

Figure 2. The influence of $\mathrm{pH}$ on the potential response of the membrane electrodes based on $\mathrm{Hg}(\mathrm{CTP})_{2}$ at (A) $1 \times 10^{-3}$ and (D) $1 \times 10^{-2} \mathrm{M}$ iodide. (C) and (B) are the corresponding curves for $\mathrm{Hg}(\mathrm{MBT})_{2}$. 
The potentiometric response of the electrodes was examined in the concentration range of $1 \times 10^{-7}$ to $0.1 \mathrm{M}$ iodide. Typical calibration plots for the electrodes based on $\mathrm{Hg}(\mathrm{MBT})_{2}$ and $\mathrm{Hg}(\mathrm{CTP})_{2}$ ionophores are shown in Figure 3. The electrodes show linear responses over the concentration range of $1 \times 10^{-6}$ to $0.1 \mathrm{M}$ with sensitivities of $-57.6 \pm 0.8$ and $-58.4 \pm 1.4$, and detection limits of $4 \times 10^{-7}$ and $6 \times 10^{-7} \mathrm{M}$ for $\mathrm{Hg}(\mathrm{MBT})_{2}$ and $\mathrm{Hg}(\mathrm{CTP})_{2}$ ionophores, respectively. The dynamic response time of the electrodes was $\leq 10 \mathrm{~s}$ under stirred conditions when the electrodes were inserted in $1 \times 10^{-4}$ to $1 \times$ $10^{-2} \mathrm{M}$ iodide solutions. Typical potential-time response of the electrode based on $\mathrm{Hg}(\mathrm{MBT})_{2}$ after addition of $5 \times 10^{-3}, 5 \times 10^{-2}, 0.5$ and $5 \mathrm{~mL}$ of $0.1 \mathrm{M}$ iodide solution to $50 \mathrm{~mL}$ of $1 \times 10^{-6} \mathrm{M}$ iodide, which was followed by a recorder, is shown in Figure 4.

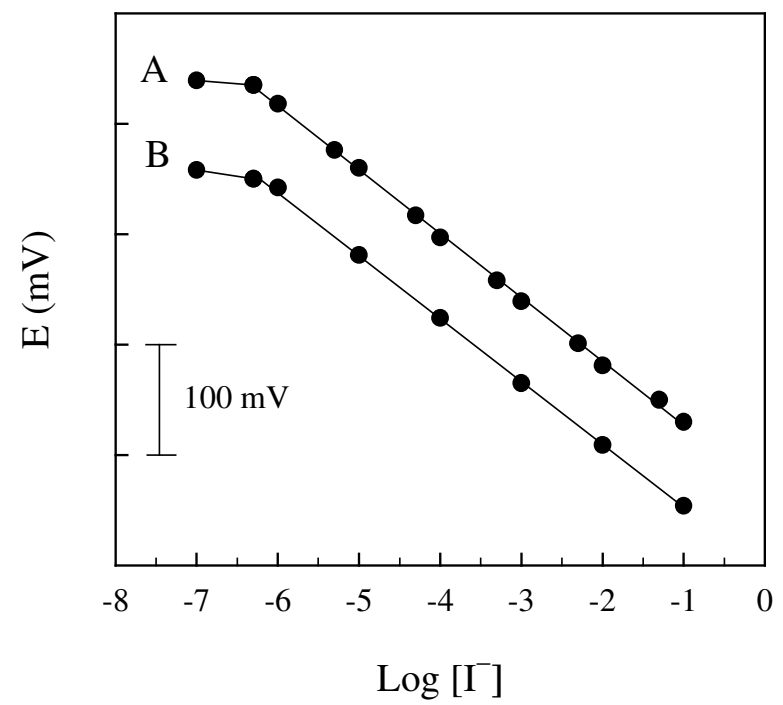

Figure. 3. Calibration plots of the electrodes based on (A) $\mathrm{Hg}(\mathrm{MBT})_{2}$ and (B) $\mathrm{Hg}(\mathrm{CTP})_{2}$ carriers. Membrane compositions and measurement conditions are given in Table 2.

The reproducibility and stability of the electrodes were tested by repeated monitoring of potentials and calibration over a period of two months. The results revealed a very slight gradual decrease in the calibration slopes of the electrodes after this period. For instance, the relative standard deviation (RSD) of the calibration slope for the same electrodes (between electrode variation) stored in $0.05 \mathrm{M}$ potassium iodide solution over periods of 15 days and 1 month were 1.7 and $2.5 \%$, respectively. Higher RSD values were observed when the electrodes were stored in ambient air or in distilled water (Table 2). The standard deviation of slope for several electrodes (within electrode variation), constructed by using the same membrane solution for $\mathrm{Hg}(\mathrm{CTP})_{2}$ and $\mathrm{Hg}(\mathrm{MBT})_{2}$ ionophores, were $-58.4 \pm 1.4$ and $-57.6 \pm 0.8 \mathrm{mV} /$ decade of iodide concentration, respectively.

The potentiometric selectivity coefficients of the coated graphite electrodes were determined by the separate solution method (SSM), using 0.01 M solutions of iodide and interfering ions, and also by the fixed interference method (FIM) using 0.01 M interfering ions and varying concentrations of iodide 
ion. Table 3 lists the potentiometric selectivity coefficients of the optimized membrane electrodes (according to Table 2) based on $\mathrm{Hg}(\mathrm{CTP})_{2}$ and $\mathrm{Hg}(\mathrm{MBT})_{2}$ ionophores. From Table 3, it can be seen that the electrodes based on both carriers are highly selective towards iodide with respect to a variety of anions. There is a satisfactory agreement between the two sets of results obtained for several anions by the FIM and SSM methods. The order of selectivity for the ionophores studied in this work clearly indicates that there is a strong and selective interaction between both of the ionophores and iodide ion. It should also be noted that almost all of the response characteristics including sensitivity, detection limit, linear range, $\mathrm{pH}$ dependency, response time and even the selectivity of the electrodes based on $\mathrm{Hg}(\mathrm{CTP})_{2}$ and $\mathrm{Hg}(\mathrm{MBT})_{2}$ ionophores are very similar. This is another indication that the interaction between iodide and the two complexes occurs at the mercury center via a specific type of interaction, and that the two ligands structures do not play a considerable role on the response of the electrodes.

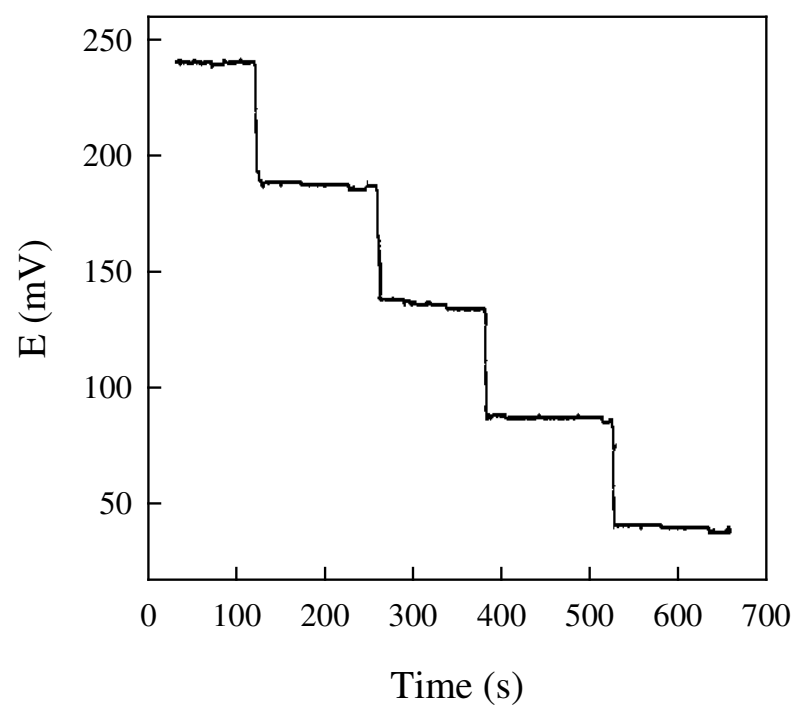

Figure 4. Typical potential-time recorder trace of the electrode based on $\mathrm{Hg}(\mathrm{MBT})$ Membrane compositions and measurement conditions are given in Table 2.

\section{Analytical applications}

The resulting electrodes were applied to the determination of iodide in a drug preparation (Meglumine Compound Injection, from Darou Pakhsh Pharmaceutical Co., Iran, is an iodide containing drug used for protection from light and secondary X-rays). The sample was prepared by refluxing $1.0 \mathrm{~mL}$ of the drug preparation in concentrated sodium hydroxide solution in the presence of zinc powder for $30 \mathrm{~min}$ [24]. After cooling, the reaction mixture was filtered and washed with water three times. The filtrate was acidified with $\mathrm{H}_{2} \mathrm{SO}_{4}$ and diluted to $1 \mathrm{~L}$ with water. The iodide content of the resulting solution was determined potentiometrically by the standard addition method. The results obtained by the electrode method are in agreement with those obtained by titration with standard $\mathrm{AgNO}_{3}$ solution as given in Table 4. 
Table 3. Selectivity Coefficients of the Coated-Graphite Electrodes Based on $\mathrm{Hg}(\mathrm{CTP})_{2}$ and $\mathrm{Hg}(\mathrm{MBT})_{2}$ Carriers.

\begin{tabular}{|l|c|c|c|c|}
\hline \multirow{2}{*}{ Ion } & \multicolumn{4}{|c|}{ Log $\boldsymbol{K}_{\boldsymbol{S C N}, \boldsymbol{i}}$} \\
\cline { 2 - 5 } & $\mathbf{H I M}(\mathbf{M B T})_{\mathbf{2}}$ & \multicolumn{2}{c|}{ Hg(CTP $)_{2}$} \\
\hline Perchlorate & -2.57 & -3.15 & -2.45 & -2.85 \\
\hline Salicylate & -4.12 & -4.62 & -3.98 & -4.36 \\
\hline Phosphate & -4.52 & -4.18 & -4.49 & -4.35 \\
\hline Azide & -4.27 & -3.65 & -4.33 & -3.84 \\
\hline Oxalate & -4.65 & -4.76 & -4.70 & -4.78 \\
\hline Bromide & -3.05 & -2.42 & -3.15 & -2.49 \\
\hline Chloride & -3.58 & -3.34 & -3.83 & -3.48 \\
\hline Carbonate & -3.98 & -4.67 & -4.05 & -4.75 \\
\hline Nitrate & -4.83 & -4.86 & -4.78 & -4.93 \\
\hline Nitrite & -4.75 & -4.83 & -4.88 & -4.92 \\
\hline Sulfate & -4.52 & -4.46 & -4.35 & -4.75 \\
\hline Thiocyanate & -2.47 & -1.18 & -2.43 & -1.22 \\
\hline Acetate & -4.78 & -4.72 & -4.53 & -4.86 \\
\hline Fluoride & -3.62 & -3.75 & -3.75 & -3.96 \\
\hline
\end{tabular}

The electrodes were also applied for the determination of iodide added to tap water samples and as indicator electrodes for potentiometric titration of silver and iodide ions. The direct potentiometric measurement was carried out using the standard addition technique. The results for the determination of iodide ion at several concentrations are in agreement with the known iodide content as given in Table 4. The electrodes were also found useful for the potentiometric titration of $\mathrm{Ag}^{+}$with iodide and vice versa. Typical titration plots are shown in Figure 5.

\section{Conclusions}

New iodide-selective solid-contact membrane electrodes have been prepared using $\operatorname{Hg}(\mathrm{CTP})_{2}$ and $\mathrm{Hg}(\mathrm{MBT})_{2}$ complexes. The electrodes have been shown to have good operating characteristics (Nernstian response; reasonable detection limit; relatively high selectivity, especially with respect to the highly lipophilic anions; wide dynamic range; fast response; applicability over a wide $\mathrm{pH}$ range). These characteristics and the typical applications presented in this paper, make the electrode suitable for measuring the iodide content in a wide variety of samples, without a significant interaction from concomitant anionic species. The results show that there was a coordination interaction between iodide and the proposed carriers, which played an important role in the response characteristics and selectivity of the electrodes. 


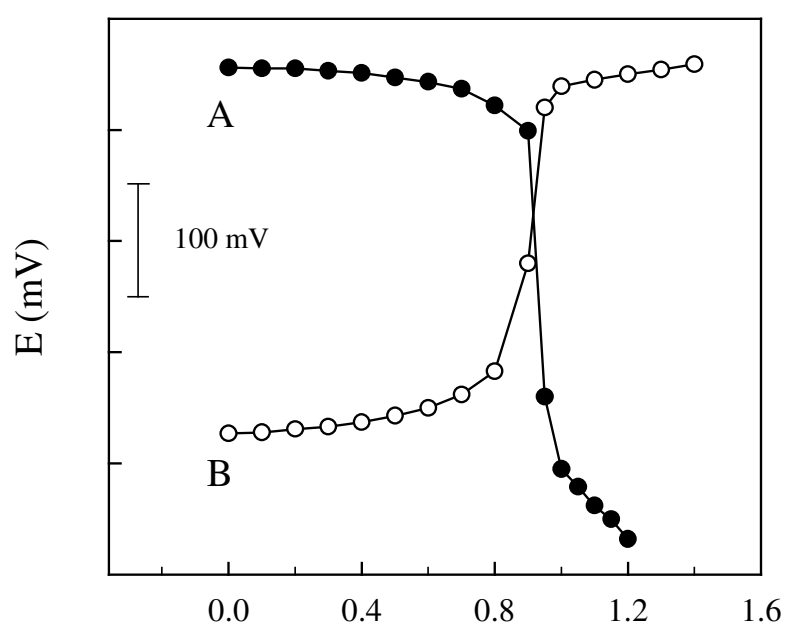

Titrant (ml, $0.1 \mathrm{M})$

Figure 5. Application of the electrode based on $\mathrm{Hg}(\mathrm{MBT})_{2}$ for potentiometric titration of (A) $100 \mathrm{~mL} 1 \times 10^{-3} \mathrm{M} \mathrm{Ag}^{+}$with $0.1 \mathrm{M} \mathrm{I}^{-}$and (B) $100 \mathrm{~mL} 1 \times 10^{-3} \mathrm{M} \mathrm{I}^{-}$with $0.1 \mathrm{M}$ $\mathrm{Ag}^{+}$. Other conditions are given in Table 2.

Table 4. Application of the Electrodes Based on $\mathrm{Hg}(\mathrm{MBT})_{2}$ and $\mathrm{Hg}(\mathrm{CTP})_{2}$ Carriers for Determination of Iodide Added to Tap Water and a Drug Preparation samples (All Concentrations are in M).

\begin{tabular}{|l|c|c|c|}
\hline Sample & Iodide added & \multicolumn{1}{|c|}{$\begin{array}{c}\text { Iodide found } \\
\text { Hg(MBT })_{2}\end{array}$} & $\begin{array}{c}\text { Iodide found } \\
\text { Hg(CTP) }\end{array}$ \\
\hline 1. (Tap Water) & - & ND & ND \\
\hline & $8.0 \times 10^{-6}$ & $(8.35 \pm 0.38) \times 10^{-6}$ & $(8.41 \pm 0.41) \times 10^{-6}$ \\
\hline & $4.6 \times 10^{-5}$ & $(1.49 \pm 0.08) \times 10^{-5}$ & $(1.52 \pm 0.0 .07) \times 10^{-5}$ \\
\hline & $8.0 \times 10^{-5}$ & $(4.18 \pm 0.18) \times 10^{-5}$ & $(4.20 \pm 0.17) \times 10^{-5}$ \\
\hline & $4.90 \times 10^{-4}$ & $(5.04 \pm 0.06) \times 10^{-4}$ & $(5.06 \pm 0.0 .06) \times 10^{-4}$ \\
\hline $\begin{array}{l}\text { 2. (Meglumine } \\
\text { Compound) }\end{array}$ & $(2.78 \pm 0.14) \times 10^{-3 *}$ & $(2.89 \pm 0.16) \times 10^{-3}$ & $(2.66 \pm 0.15) \times 10^{-3}$ \\
\hline
\end{tabular}

Iodide concentration in the sample was obtained by titration with $\mathrm{AgNO}_{3}$ solution. 


\section{Acknowledgement}

The authors express their appreciation to the Graduate School and Research Council of the University of Isfahan for financial support of this work.

\section{References}

1. Jakmunee, J.; Grudpan, K. Flow injection amperometry for the determination of iodate in iodized table salt. Anal. Chim. Acta 2001, 438, 299-304.

2. Shin, H. S.; Oh-Shin, Y. S.; Kim, J. H.; Ryu, J. K. Trace Level determination of Iodide, Iodine and Iodate. J. Chromatogr. A 1996, 732, 327-333.

3. Bichsel, Y.; Von-Gunten, U. Determination of Iodide and Iodate by Ion Chromatography With Post Column Reaction and UV/Visible Detection. Anal. Chem. 1999, 71, 34-38.

4. Buchberger, W.; Ahrer, W. Combination of Suppressed and non-Suppressed Ion Chromatography With Atmospheric Pressure Ionization Mass Spectrometry for the Determination of Anions. J. Chromatogr. A 1999, 850, 99-106.

5. Larsen, E. H.; Ludwigsen, M. B. Determination of Iodine in Food-Related Certified Reference Materials Using Wet Ashing and Detection by Inductively Coupled Plasma Mass Spectrometry. J. Anal. At. Spectom. 1997, 12, 435-440.

6. Hou, X.; Dahlgaard, H.; Rietz, B.; Jacobsen, U.; Nielsen, S. P. Aarkrog, A. Determination of Chemical Species of Iodine in Seawater by Radiochemical Neuton Activation Analysis Combined With Ion-Exchange Preseparation. Anal. Chem. 1999, 71, 2745-2750.

7. Fujiwara, T.; Mohammadzai, H.; Inoue, H.; Kumamaru, T. Chemiluminescence Determination of Iodide and/or Iodine Using Luminol-Hexadecyltrimethylammonium Chloride Reversed Micelle System Following On-line Oxidation and Extraction. Analyst 2000, 125, 759-763.

8. Turner, J.A.; Abel, R.H.; Osteryoung, R. A. Normal Pulse Polarographic Analysis Based on Mercury Anodization. Sulfide and Iodide. Anal. Chem. 1975, 47, 1343-1347.

9. Prost, R.C. Cathodic Pulse Stripping Analysis of Iodide at the Parts-Per-Billion Level. Anal. Chem. 1977, 49, 1199-1205.

10. Svancara, I.; Konvalina, J.; Schachl, K.; Vytras, K. Stripping Voltammetric Determination of Iodide With Synergistic Accumulation at a Carbon Paste Electrode. Electroanalysis 1998, 10, 435-441.

11. Yeom, J.-S.; Won, M.-S.; Shim, Y.-B. Voltammetric Determination of Iodide Ion With Quinine Copper(II) Complex Modified Carbon Paste Electrode. J. Electroanal. Chem. 1999, 463, 16-23.

12. Håkedal, J. T.; Egeberg, P. K. Determination of Iodide in Brines by Membrane Permeation Flow Injection Analysis. Analyst 1997, 122, 1235-1237.

13. Yonehara, N.; Kozono, S.; Sakamoto, H. Flow Injection Spectrophotometric Determination of Trace Amounts of Iodide by its Catalytic Effect on the 4,4'-Bis(diethylamino)diphenylmethaneChloramine T Reaction. Anal. Sci. 1991, 7, 229-234.

14. Daunert, S.; Wallace, S.; Florido, A.; Bachas, L. G. Anion-Selective Electrodes Based on Polymerized Porphurin Films. Anal. Chem. 1991, 63, 1676-1679.

15. Daunert, S.; Florido, A.; Bricker, J.; Dunaway, W.; Bachas, L. G.; Valiente, M. Iodide-Selective 
Electrodes Based on a Mercury Triisobutylphosphine Sulfide Complex. Electroanalysis 1993, 5, 839-843.

16. Bricker, J.; Daunert, S.; Bachas, L. G. Selective Electrodes for Silver and Anions Based on Polymeric Membranes Containing Complexes of Triisobutylphosphine Sulfide with Silver. Anal. Chem. 1991, 63, 1585-1589.

17. El Aamrani, F. Z.; Sastre, A.; Aguliar, M.; Beyer, L.; Florido, A. Iodide-Selective Electrodes Based on the Silver(I) Complex of a Novel N-thiocarbamoylimine-dithioether Derivative. Anal. Chim. Acta 1996, 329, 247-252.

18. El Aamrani, F. Z.; Garcia-Raurich, J.; Sastre, A.; Beyer, L.; Florido, A. PVC Membrane Based on Silver(I)-Thiourea Complexes. Anal. Chim. Acta 1999, 402, 129-135.

19. Szczepaniak, W.; Ren, M. Selectivity of Liquid Membrane Electrode Based on Mercurated Polystyrene as Ion Exchanger to Anionic Surfactants and Soaps. Electroanalysis 1994, 6, 341347.

20. Szczepaniak, W. Mercurated Polystyrene as a Sensor for Anionic Surfactants in Ion-Selective Polymeric Membrane Electrodes. Analyst 1990, 115, 1451-1455.

21. Song, Y.-Q.; Yuan, R.; Ying, M.; Li, Z.-Q.; Chai, Y.-Q.; Cui, H.; Shen, G.-L.; Yu, R.-Q. A Highly Selective Iodide Electrode Based on Bis(benzoin)semi-ethylenediamine Complex of Mercury(II) as a Carrier. Fresenius' J. Anal. Chem. 1998, 360, 47-51.

22. Yuan, R.; Chai, Y.-Q.; Liu, D.; Gao, D.; Li, J.-Z.; Yu, R.-Q. Schiff Base Complexes of Cobalt(II) as Neutral Carriers for Highly Selective Iodide Electrodes. Anal. Chem. 1993, 65, 2572-2575.

23. Li, Z.-Q.; Yuan, R.; Ying, M.; Song, Y.-Q.; Shen, G.-L.; Yu, R.-Q. Iodide Selective PVC Membrane Electrodes Based on Five Transitional Metal Chelates of Bis-furfural-semi-otolidine. Anal. Lett. 1997, 30, 1455-1464.

24. Ying, M.; Yuan, R.; Zhang, X.-M.; Song, Y.-Q.; Li, Z.-Q.; Shen, G.-L.; Yu, R.-Q. Highly Selective Iodide Poly(vinyl chloride) Membrane Electrode Based on Nickel(II) Tetraazaannulene Macrocyclic Complex. Analyst 1997, 122, 1143-1146.

25. Lizondo-Sabater, J.; Martínez-Máñez, R.; Sancenón, F.; Seguí, M.-J.; Soto, J. Cobalt(II) and Nickel(II) Complexes of a Cyclam Derivative as Carriers in Iodide-Selective Electrodes. Anal. Chim. Acta 2002, 459, 229-234.

26. Fu, Y.; Wu, T.; Li, B.; Sun, C. Fabrication of a Covalently Attached Multilayer Film Electrode Containing Cobalt Phthalocyanine and its Applications as a Potentiometric Sensor of Iodide Ion. Anal. Chim. Acta 2002, 455, 61-68.

27. Daunert, S.; Bachas, L. G. Anion-Selective Electrodes Based on Hydrophobic Vitamin $B_{12}$ Derivative. Anal. Chem. 1989, 61, 499-503.

28. Shamsipur, M.; Sadeghi, S.; Naeimi, H.; Sharghi, H. Iodide Ion-Selective PVC Membrane Electrode Based on Recently Synthesized Salen-Mn(II) Complex. Polish J. Chem. 2000, 74, 231-238.

29. Shamsipur, M.; Soleymanpour, A.; Akhond, M.; Sharghi, H.; Naseri, M. A. Iodide-Selective Carbon Paste Electrodes Based on Recently Synthesized Schiff Base Complexes of Fe(III). Anal. Chim. Acta 2001, 450, 37-44.

30. Alexander, P. W.; Dimitrakopoulos, T.; Hibbert, D. B. A Six Sensor Array of Coated-Wire 
Electrodes for Use in a Portable Flow Injection Analyzer. Electroanalysis 1998, 10, 707-712.

31. Rover, L. Jr.; Garcia, C. A. B.; de Oliveira-Neto, G.; Kubota, L. T.; Galembeck, F. Acetylsalicylic Acid Determination in Pharmaceutical Samples by FIA Potentiometry Using a Salicylate-Selective Tubular Electrode With an Ethylene-Vinylacetate Membrane. Anal. Chim. Acta 1998, 366, 103-109.

32. De Backer, B. L.; Nagels, L. J. Potentiometric Detection for Capillary Electrophoresis: Determination of Organic Acids. Anal. Chem. 1996, 68, 4441-4445.

33. Kappes, T.; Schnierle, P.; Hauser, P. C. Potentiometric Detection of Inorganic Anions and Cations in Capillary Electrophoresis With Coated Wire Ion Selective Electrodes. Anal. Chim. Acta 1997, 350, 141-147.

34. Schnierle, P.; Kappes, T.; Hauser, P. C. Capillary Electrophoresis Determination of Different Classes of Organic Ions by Potentiometric Detection With Coated-Wire Ion Selective Electrodes. Anal. Chem. 1998, 70, 3585-3589.

35. Sanchez-Pedreno, C.; Ortuno, J. A.; Alvarez, J. Coated-Wire Ion-Selective Electrode for the Determination of Antimony(V) Anal. Chem. 1991, 63, 764-766.

36. Cha-Lun, H.; Ren, J. J.; Da-Feng, X. Studies of the Chloropheniramine Solid-State Ion-Selective Electrode. Talanta 1996, 43, 2061-2065.

37. Yang, Y. H.; Bi, Y. M.; Liu, M.; Fu, J.; Xi, Z. W. The Properties of a Decylidene-bis(4-benzo15-crown-5) Ether Membrane Rubidium(I) Electrode. Microchem. J. 1997, 55, 348-350.

38. Amini, M. K.; Shahrokhian, S.; Tangestaninejad, S. PVC-Based Mn(III) Porphyrin MembraneCoated Graphite Electrode for Determination of Histidine. Anal. Chem. 1999, 71, 2502-2505.

39. Amini, M. K.; Shahrokhian, S.; Tangestaninejad, S. Porphyrins as Carriers in Poly(vinyl chloride)-Based Membrane Potentiometric Sensors for Histamine. Analyst 1999, 124, 13191322.

40. Khalil, S. Ion-Selective Electrode for the Determination of Trazodone in Tablets. Analyst 1999, 124, 139-142.

41. Amini, M. K.; Shahrokhian, S.; Tangestaninejad, S. Thiocyanate Selective Electrodes Based on Nickel and Iron Pphthalocyanines. Anal. Chim. Acta 1999, 402, 137-143.

42. Missel, P. J. Coated-Wire Ion-Sselective Electrode for Levobetaxolol. Langmuir 1999, 15, $7122-7124$

43. Xu, R.; Bloor, D. M. Preparation and Properties of Coated-Wire Ion Selective Electrodes for Anionic and Cationic Surfactant. Langmuir 2000, 16, 9555-9558.

44. Shahrokhian, S.; Amini, M. K.; Kia, R.; Tangestaninejad, S. Salicylate-Selective Electrodes Based on Al(III) and Sn(IV) Salophens. Anal. Chem. 2000, 72, 956-962.

45. Khaled, E. E.; Hassan, H. N. A.; Barsoum, B. N.; Vytras, K. Kinetic Catalytic Determination of Trace Nitrite Based on the Oxidation of Malachite Green With Bromate Monitored Potentiometrically Using Coated-Wire Electrodes. Electroanalysis 2001, 13, 3338-3341.

46. Ueyama, N.; Taniuchi, K.; Okamura, T.; Nakamura, A.; Maeda, H.; Emura, S. Effect of NH-S Hydrogen bond on the Nature of $\mathrm{Hg}-\mathrm{S}$ Bonding in Bis[2-(acylamino)benzenethiolato] Mercury(II) and Bis[2,6-bis(acylamino)benzenethiolato] Mercury(II) Complexes. Inorg. Chem. 1996, 35, 1945-1951.

47. Bell, N. A.; Coles, S. J.; Constable, C. P.; Hibbs, D. E.; Hursthouse, M. B.; Mansor, R.; Raper, 
E.S.; Sammon, C. Complexes of Heterocyclic Thiones and Group 12 Metals, Part 5. Reactions of 1,3-Thiazolidine-2-thione and Benzo-1,3-thiazoline-2-thione With Mercury(II) Halides in a 2:1 Ratio: Crystal Structure of Bis(1,3-thiazolidine-2-thione) Mercury(II) Bromide and Bis(benzo-1,3-thiazolinato) Mercury(II). Inorg. Chim. Acta 2001, 323, 69-77.

48. Skoog, D. A.; West, D. M.; Holler, F. J. Fundamentals of Analytical Chemistry, $6^{\text {th }}$ Ed., Saunders College Publishing, New York, 1991; p 819.

Sample Availability: Available from the authors.

(C) 2003 by MDPI (http://www.mdpi.org). Reproduction is permitted for noncommercial purposes. 